\title{
Arte, terapia y mujeres migrantes. Caso Kauthar. El espejo es la frontera
}

\author{
Laura RICO CABALLO ${ }^{1}$ \\ lrcaballo@cop.es
}

Recibido: $30 / 06 / 12$

Aceptado: 22/11/12

\begin{abstract}
RESUMEN
Khautar, nació en Marruecos, lleva en España más de 20 años. A pesar de ello su vida social ha sido mínima. Tras conocer la experiencia de sus hijas en el taller, un día se acerca a probar... Con su caso se expone un ejemplo de intervención terapéutica grupal en migración a través de arte.El proceso migratorio es complejo. Tras la aparente integración se esconden a veces muchas trampas, silencios y concesiones culturales inestables. Khautar se atreve a iniciar otro viaje, el de la búsqueda de sí misma y la participación activa en el espacio en el que hace años vive.
\end{abstract}

Palabras clave: Arte, terapia, arteterapia, mujer, migración.

\section{Referencia normalizada}

Rico Caballo. L. (2012). "Arte, terapia y mujeres migrantes. Caso Kauthar. El espejo es la frontera". En Arteterapia: Papeles de arteterapia y educación artística para la inclusión social Vol.7: páginas 141-151. Madrid. Servicio de publicaciones UCM.

\section{SUMARIO}

Metodología: Evaluación. Mujer, migración y arte. Khautar. La obra de Khautar. La primera sesión: Escoge un valor. Las primaveras árabes. Nunca he hecho una pintada. Los buenos recuerdos. Cáncer y mujer. Arteterapia para el corazón. El deseo. Espacio II. El lugar de nacimiento. Pañuelos. La experiencia de participar en actividades externas. Evolución y beneficios para Khautar del taller.

\section{Art, therapy and women migration. case: kauthar. The mirror is the border.}

\begin{abstract}
Khautar, born in Morocco, has been living in Spain for over 20 years. However her social life has been minimal. After knowing her daughter's experience at the workshop, one day she decides to try... With her case an example of group therapeutic intervention in migration through art is told. The migration process is complex. Behind the apparent integration many traps, silences and cultural concessions unstable are sometimes hidden. Khautar dares to start another journey: that of finding herself and the active participation in the space in which she has been living for years.
\end{abstract}

Keywords: Art, therapy, Art therapy, woman, migration.

\footnotetext{
${ }^{1}$ Psicóloga-Arteterapeuta. Doctora en Educación. Miembro del "Foro Iberoamericano de Arteterapia". Profesora Máster de Arteterapia UCM. Coordinadora de los talleres de arte "Ventillarte", Pueblos Unidos. http://www.psicologiayterapias.com/
} 


\section{CONTENTS}

Methodology: Evaluation. Women, migration and art. Khautar.The work of khautar. The first session: Choose a value. The Arabic Spring. I never made a painting. Good memories. Cancer and women. Art therapy for the heart. Desire.Space II. The birthplace. Scarves. The experience of participating in outside activities. Evolution and benefits of Khautar's Workshop.

Desde 2004 se vienen realizando en Pueblos Unidos talleres de intervención psicosocial con arte. A través del taller se trabajan temas personales y/o colectivos que los especialistas y los usuarios del centro entienden que son importantes para su desarrollo personal y comunitario. Se conocen por el nombre de Ventillarte.

\section{METODOLOGÍA ${ }^{2}$}

Nos basamos en el método investigación-acción ${ }^{3}$ y en el contexto actual de crisis intentamos introducir las directrices de la psicología generativa que busca producir el cambio positivo a través de la intervención directa (Moghaddam $\left.{ }^{4} 1990,1998\right)$.

\section{Evaluación}

Los profesionales llevan registros cualitativos y cuantitativos que permiten las evaluaciones trimestrales. Los arteterapeutas deben asistir a las reuniones generales del centro en las que pueden recabar más información de los participantes desde otras perspectivas y deben aportar su visión en ellas. Se tiene entrevistas continuas con los participantes y, en algunos casos, visitas domiciliarias.

\section{Mujer, migración y arte. Khautar}

Khautar (nombre ficticio), que nació en Marruecos, lleva en España más de 20 años. A pesar de ello su vida social ha sido mínima. Tras conocer la experiencia de sus hijas adolescentes en el taller un día se acerca a probar...

Khautar no es igual a nadie, ni su experiencia es común a la de ninguna otra mujer en el sentido de que es un ser único e irrepetible como cada individuo tiene el

\footnotetext{
${ }^{2}$ Para más información: Rico Caballo, L (2012) Frente a la maldición de Babel. Terapia, arte y migraciones. Arteprosocial en sociedades dinámicas. Editorial Psimatica. Madrid.

Rico Caballo, L, Izquierdo Jaén, Gloria (2010) Arte en Contextos Especiales. Inclusión Social y Terapia a través del Arte. Trabajando con Niños y Jóvenes Inmigrantes Arteterapia. Papeles de Arteterapia y Educación Artística para la Inclusión Social. UCM. Madrid. Disponible en: http://revistas.ucm.es/index.php/ARTE/article/view/ARTE1010110153A/8735. Fecha de acceso: 04 may. 2012.

En video: http://www.youtube.com/watch?v=KgszClZsil8

${ }^{3}$ La sociología ha desarrollado ampliamente este método conocido como Investigación Acción Participativa (IAP) y del que empezó a hablar Kurt Lewin (1944) para describir una forma de investigación que podía ligar el enfoque experimental de la ciencia social con programas de acción social que respondieran a los problemas sociales pudiendo lograr simultáneamente avances teóricos y cambios sociales. Sus teorías se expandieron entre los años 60 y 70 y hoy han dado lugar a líneas variadas de trabajo.

${ }^{4}$ Moghaddam, F. (1990). Modulative and generative orientations in psychology: Implications for psychology in the three worlds. Journal of Social Issues, 46, 21-41. Moghaddam, F. (1998). Social Psychology: Exploring universals across cultures. New York: Freeman.

${ }^{5}$ Se agradece a las arteterapeutas Laura Carmona y Julia Sánchez su colaboración y reflexiones para el caso
} 
derecho de ser. Dentro de esta circunstancia ella puede reflejar a la mujer trabajadora que emigró de niña y tras décadas de estancia en el mismo país sigue luchando por encontrar su espacio y un espacio para su familia. Porque ¿Cuándo y cómo deja uno de ser inmigrante? ¿Depende de la mirada propia o de la de los otros?

Nacida en Tánger comenzó a trabajar a los 8 años en una fábrica de alfombras. Recuerda que allí le pegaban cuando cometía errores y establece una narrativa positiva pensando que aquello la sirvió para aprender mucho y deprisa. A los 14 años llegó a Madrid apoyada por su hermana que ya estaba en la ciudad en el servicio doméstico. En esa casa aprendió el idioma y las primeras bases de la lectura... "Khautar, tienes que salir, ver cosas, estudiar, aprender. No estés siempre encerrada", cuenta que le decía la dueña de la casa. Pero Khautar era joven, tenía miedo a muchas cosas y pocas facilidades para tomarse esa libertad. A los 25 llegó el momento de casarse. Khautar ya estaba establecida en España con todos sus permisos, el sueño de muchos y eso la convertía en alguien muy codiciado y había que saber escoger. En unas vacaciones breves en Marruecos conoció a un chico que les producía confianza. El matrimonio fue aprobado y juntos volvieron a Madrid. Y llegaron las niñas: Soraya, Layla y Widad que ahora tienen 16, 14 y 10 años. Durante este tiempo Khautar ha trabajado fuera de casa mientras se ocupaba de la crianza de sus niñas (a las que debía llevar al trabajo de bebes). En este momento las tres chicas son unas adolescentes sanas, estudiosas y prometedoras. Y Khautar se plantea nuevas cosas en su vida. Cosas que relegó... y por eso ha llegado al taller de Ventillarte.

Khautar cantaba bien cuando trabajaba en la fábrica de tapices de niña pues recuerda que aprendía rápido las canciones de las bodas y la pedían los compañeros que cantara. En cambio Khautar no había pintado nunca. No hubo tiempo en su infancia, ni en la juventud: "yo no sé dibujar, nunca he dibujado" Le cuesta enfrentarse a las propuestas plásticas de los arteterapeutas pero lo hace igual que vive: rápido, valiente y superando sus temores y sus inseguridades. Se incorporó con el curso ya empezado pero dispuesta a la mayor de las formalidades, es puntual, trae su propio estuche con algo de material y quiere sacar de cada sesión lo máximo. A veces es complicado ajustar su ritmo alto al del grupo.

Para Soraya, su hija mayor, Khautar es así:

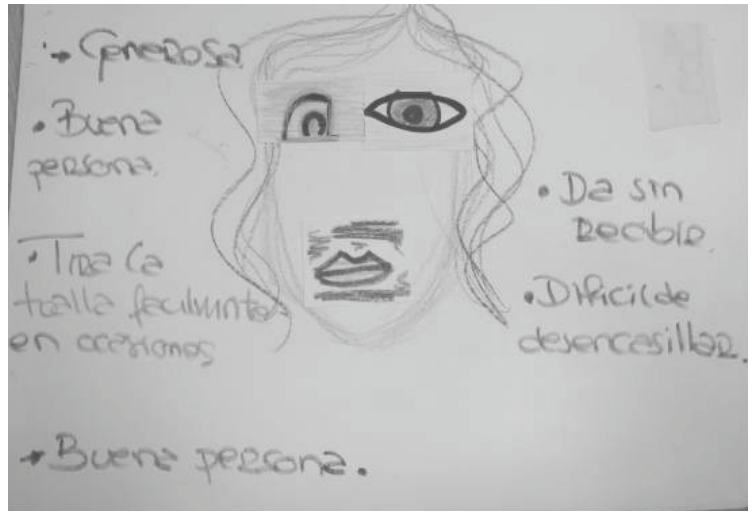




\section{LA OBRA DE KHAUTAR}

\section{La primera sesión. Escoge un valor.}

En esa sesión Khautar escogió para trabajar las palabras: Valor y Alegría. Fue su primer día de taller, el primer contacto con el grupo y una declaración de intenciones.

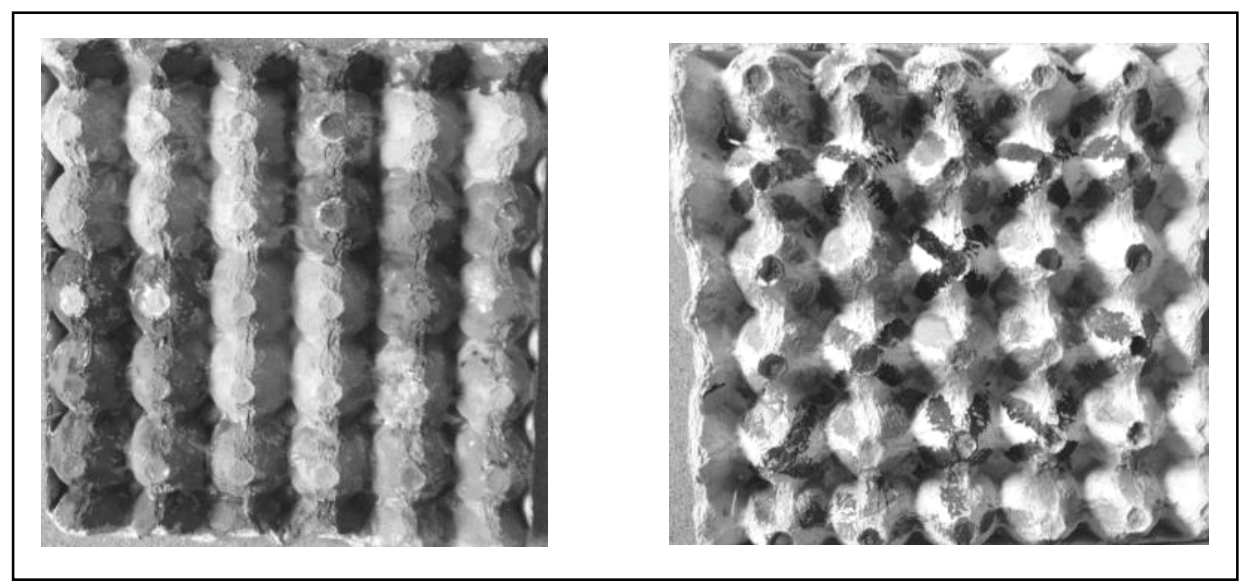

\section{Avatares de la inmigración: cine y música West Side Story}

Tras la película West Side Story, en concreto la canción América, se abre un debate sobre la integración en distintos tiempos y países y los matrimonios o parejas mixtas en procedencia o religiones. Khautar participó activamente en el debate, mostró una actitud tolerante pero prudente. Su hermana mayor está casada con un español pero el grupo lo desconocía. Habló de las dificultades que conllevaría un matrimonio entre un español y una marroquí dejando claro que su postura era de comprensión pero no la de todos, incluidos miembros de su familia. Sobre su obra, una acuarela, comenta que está intentando dibujar una persona. Trabaja rápido y con energía por lo que le da tiempo a iniciar una nueva obra. Experimenta técnicas diferentes después de lo cual el resultado no le satisface y lo deshecha seleccionando la primera obra como

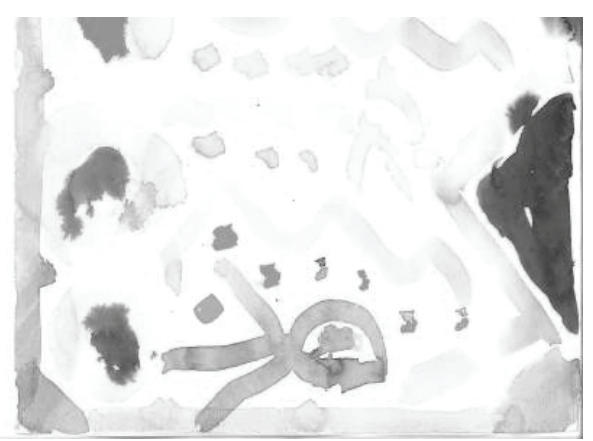
la representante de su sesión del día. 


\section{Las primaveras árabes. Nunca he hecho una pintada}

Khautar escribió, dibujó una

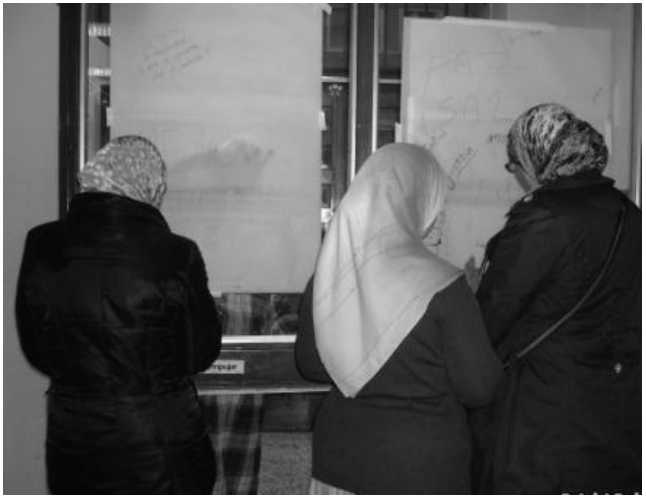
flor y continuó en la pancarta de al lado donde dibujó una mano al ver a otra compañera hacerlo. Siguiendo con su experimentación sobre la figura humana dibujó también un muñeco contento ("es lo único que sé dibujar"). Muy participativa, expuso su opinión sobre la televisión de Marruecos, sobre la participación de la mujer marroquí en política o la corrupción y el dinero público en distintos países.

\section{Los buenos recuerdos}

Entre las desdichas de la crisis económica buscamos el aliento de lo positivo. Pedimos recordar, a través de un objeto o un dibujo, un recuerdo positivo que nos hace sonreír. Khautar escoge el recuerdo de su primer cumpleaños. Se refiere a su primera celebración de cumpleaños ¡a los 16 años! Los dueños de la casa en la que trabajaba como empleada doméstica y niñera la llamaron a ordenar un trastero que ella creía ordenado pero lo que la esperaba era una fiesta sorpresa con su primera tarta y sus primeros regalos envueltos, nuevos y radiantes...

El recuerdo de Khautar formo luego parte de una videocreación con las imágenes y la voz de todas las compañeras recordando su vida que se presentó en el II En-

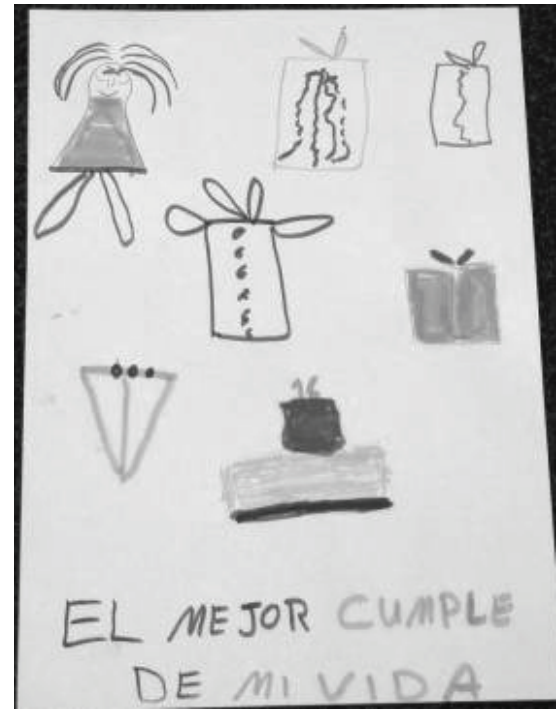
cuentro de Salud Tetuán (distrito de Madrid al que pertenece el grupo).

\section{Cáncer y mujer. Arteterapia para el corazón}

En esta sesión visita el taller una artista arteterapeuta que nos habla sobre su experiencia con el cáncer de mama. Es una sesión emocionante tras la que se les pide que intenten hacer un trabajo que refleje su dolor, el que sea, y que después lo tiren, quemen, guarden o escojan el destino que desean para él. También se les pide que piensen una palabra positiva para enfrentarlo o equilibrarlo. 
La figura de la derecha es su primer intento de reflejar su dolor: un fuerte dolor lumbar ${ }^{6}$. Previamente ha visto dibujos de Frida Khalo y su columna. Insatisfecha por el resultado la deshecho e hizo la figura de la izquierda con un texto "Viva la vida".
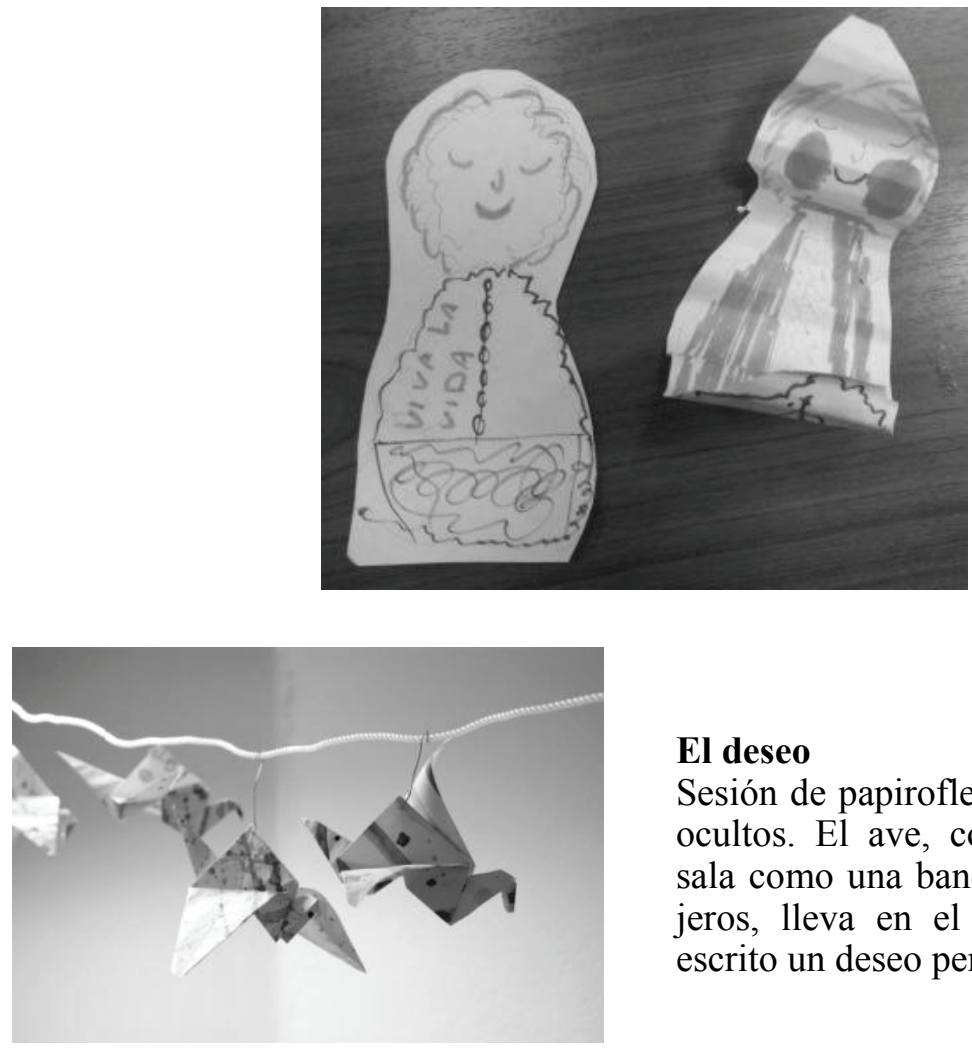

\section{El deseo}

Sesión de papiroflexia sobre los deseos ocultos. El ave, colgados todos en la sala como una bandada de pájaros viajeros, lleva en el interior del vientre escrito un deseo personal y secreto.

\section{Espacio II. El lugar de nacimiento}

Aunque Khautar aun no asistía al taller entonces, el resto del grupo ha trabajado en una sesión anterior "Su espacio favorito en el momento presente". Este segundo ejercicio lo complementa preguntándoles por "Su espacio favorito de la infancia" y por tanto del lugar de origen.

${ }^{6}$ Depresión, dolor de espalda y migraña están entre las quejas más referidas en salud mental por las inmigrantes. En nuestro taller coincide. 


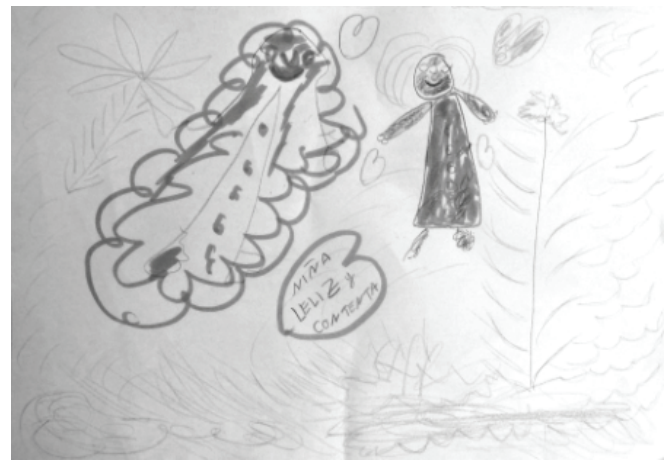

Khautar es de Tánger. Con frecuencia nos habla de las noches de verano en la ciudad cuando vuelven todos para las vacaciones, de la animación de las calles y de las familias compartiendo el espacio juntas. Ahora recuerda su infancia como una etapa muy feliz en su vida. Destaca el hecho de jugar en el campo, deslizarse montados en cajas de cartón con sus amigas. Recuerda también divertida las regañinas de su abuela por esta conducta que le parecía peligrosa especialmente para las chicas solteras. Cuando todas cogen el papel ella se anima y se pinta rodeada de corazones y elementos del campo y la naturaleza. La figura morena y sonriente, con traje rosa largo, tiene debajo un corazón que dice "niña feliz y contenta".

\section{Pañuelos}

En esta sesión abordamos un tema tan personal y a veces conflictivo como el pañuelo que cubre sus cabezas. Lo combinamos con el trabajo sobre textiles que relacionamos con la artista alemana Cosima Von Bonin y sobre lo que continuaremos en sesiones posteriores.

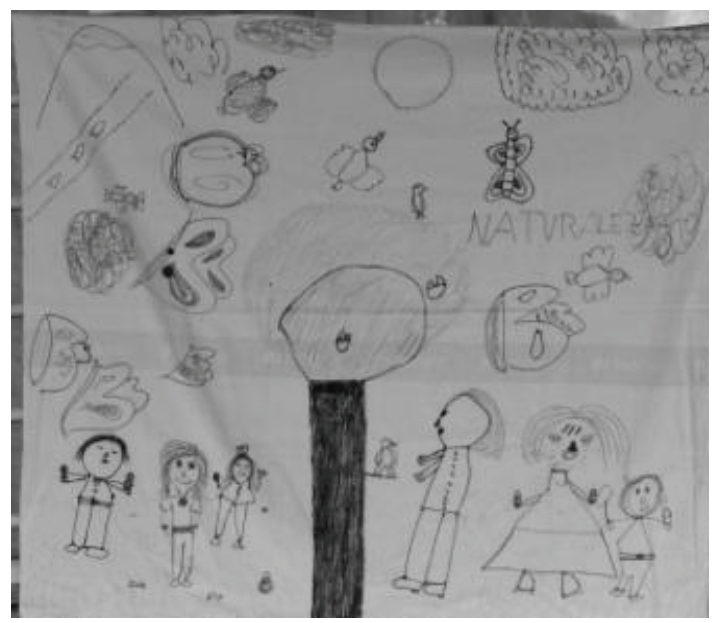




\section{La experiencia de participar en actividades externas}

El 8 de Marzo bajo el título Miradas de Mujer distintas Instituciones Culturales organizaron un programa para festejar y compartir. Dentro de estos, las mujeres del Aula Intercultural, colaboraron con el Museo Thyssen de Madrid siendo guías por un día. Junto a los cuadros han comentado con los visitantes la historia escondida en el lienzo y han compartido la forma en la que ellas entendían la obra.

Pueblos Unidos se presentaba bajo el anuncio "Mujeres que rompen fronteras", ya sea como artistas, como viajeras o como protagonistas en escenarios de conflicto. Rompiendo también estereotipos ocupamos, aunque sea por una vez, espacios en los que normalmente no suele verse a la mujer inmigrante o a la mujer musulmana, o a la mujer con velo ¿Por qué?

Khautar presentó una obra de una artista rusa de principio de siglo cuyo cuadro retrataba una escena de pesca ambiente familiar en Tánger: "vemos tres familias de pescadores... y todos van descalzos" explicaba delante del lienzo conectando plenamente con la obra al público porque el artista está donde es posible esa emoción y la sincronía entre dos miradas. Daba la vida al museo y lo conectaban con la realidad.

Es importante trabajar tanto aspectos íntimos en el recogimiento del grupo como complementar esto con salidas a otros entornos donde poder mostramos, conocer a los otros y dejarnos conocer más allá de todos los prejuicios y los patrones pre asig-

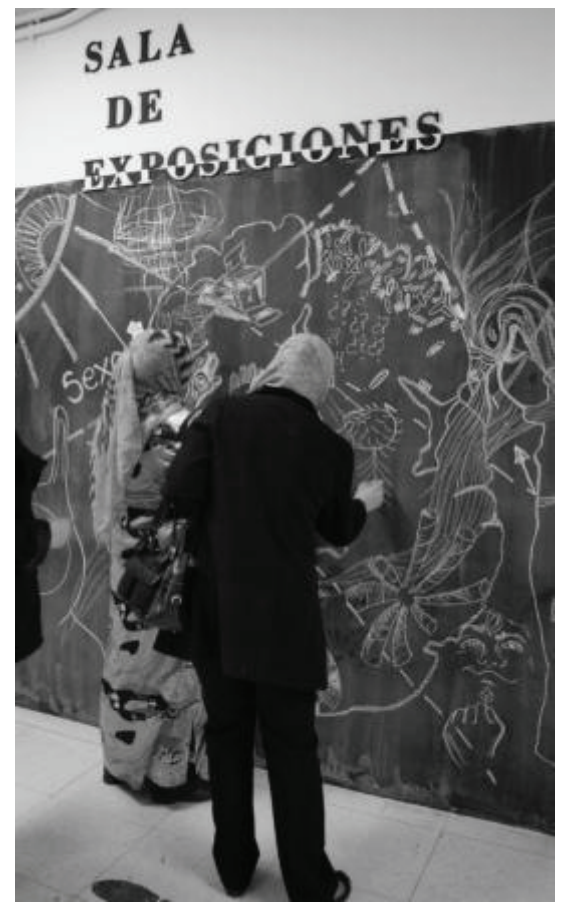
nados por cultura, género, clase social, etc. Estos trabajos de reflexión y de compartir mejoran no sólo la salud individual sino también la social. El 8 de marzo fue una nueva oportunidad de visibilizar a la mujer inmigrante en contextos positivos y de construcción conjunta.

Khautar atesora la foto de ese día que la sitúa en un rol nuevo que la gusta. Otro buen recuerdo y el inicio de un camino abierto a muchas experiencias ricas. En este caso el arte es el vehículo.

Khautar ha participado también en actividades organizadas por los estudiantes de Bellas Artes en la Facultad de la UCM como la creación de estanques con Espacio POOL y está formando parte de un grupo de colaboración con un Centro de Mayores cuyo objetivo es representar el curso que viene en espacios infantiles cuentos recreados a partir de material fabricado por este grupo.

Khautar en la Facultad de Bellas Artes participando de distintas propuestas 


\section{Evolución y beneficios para Khautar del taller}

En el caso de Khautar, de un lado están los objetivos generales del taller y de otro, pero no contrapuestos, los objetivos particulares que se van definiendo con sus aportaciones verbales. De los objetivos generales ${ }^{7}$ Khautar es un ejemplo de aprovechamiento en todos.

A nivel particular Khautar no necesitaba mejorar su lenguaje, ni su comprensión del país de acogida pues ya lleva muchos años y ha manejado estos asuntos con éxito. Khautar es una mujer que busca en un punto determinado de su vida su lugar. Dentro de esta búsqueda ha tenido oportunidad en el taller de echar un vistazo al pasado, a su infancia y su juventud, sus orígenes, lo que aprendió y lo que utilizó en los primeras años. Podemos ver por ejemplo los trabajos sobre Tánger o su 16 cumpleaños.

Hay también trabajo sobre el presente, desde lo social a lo personal: qué ocurre con su país de origen ahora, cómo es el mundo en el que se mueven sus hijas, cómo puede entenderlo y con ello ayudarlas, cómo se entiende aquí y ahora la salud de la mujer, sus deseos, su trabajo, o sus derechos.

Y finalmente hay trabajos de proyección hacia el futuro en los que va descubriendo lo que puede hacer y hacia donde puede caminar. En esta línea está explorando nuevas posibilidades en ella misma y en el entorno. Sale a sitios diferentes y con un rol nuevo, como en el caso del Thyssen o la Facultad de Bellas Artes, se escucha hablar, cada vez más segura ante un grupo sobre sus ideas y sus experiencias y siente como el grupo lo valora o en ocasiones lo rebate y lo cuestiona. Es el principio de una mujer más madura, más segura y con ilusión activa, la que nunca perdió aunque tuvo que supeditar en muchas ocasiones.

Ella quiere también cumplir unos deseos formales, casi académicos, de saber sobre arte, utilizar técnicas, trabajar con materiales y propuestas que nunca le fueron permitidos. Con ello también pone a prueba sus capacidades y descubre que aprende y que su mente, sigue viva, capaz y receptiva pues en ocasiones expresó dudas sobre las posibilidades, su edad, sus circunstancias, la pérdida de memoria, el sentimiento de tener menos agilidad mental o incluso algo tan triste como el haber perdido oído y no poder cantar como lo hacía de niña... poco a poco va sintiendo que puede y puede mucho...

Llevar adelante esa búsqueda entre otras mujeres que proceden de su misma educación y comparten experiencias lo hace más cómodo. Es cierto que ella es veterana en España pero también lo son otras y entre todas ayudan a las recién llegadas lo cual también confiere un rol valioso.

\footnotetext{
${ }^{7}$ Rico Caballo, L (2012) Frente a la torre de Babel: Terapia, arte y migraciones. Editorial Psimatica. Madrid.

Rico Caballo, L, Izquierdo Jaén, Gloria (2010) Arte en Contextos Especiales. Inclusión Social y Terapia a través del Arte. Trabajando con Niños y Jóvenes Inmigrantes Arteterapia. Papeles de Arteterapia y Educación Artística para la Inclusión Social. UCM. Madrid. Disponible en: http://revistas.ucm.es/index.php/ARTE/article/view/ARTE1010110153A/8735. Fecha de acceso: 04 may. 2012.
} 
Khautar se nos presentó como una mujer muy nerviosa (algunos trastornos somáticos en esta línea), con poca-nula participación social y dando muestras de baja autoestima en aspectos relevantes a pesar de tener un alto potencial. En apenas diez sesiones la hemos visto abrirse a la vida y brillar.

Registros para evaluar indicadores. Ejemplos de Khautar y su análisis estadístico a partir de la ficha de evaluación de Taller general
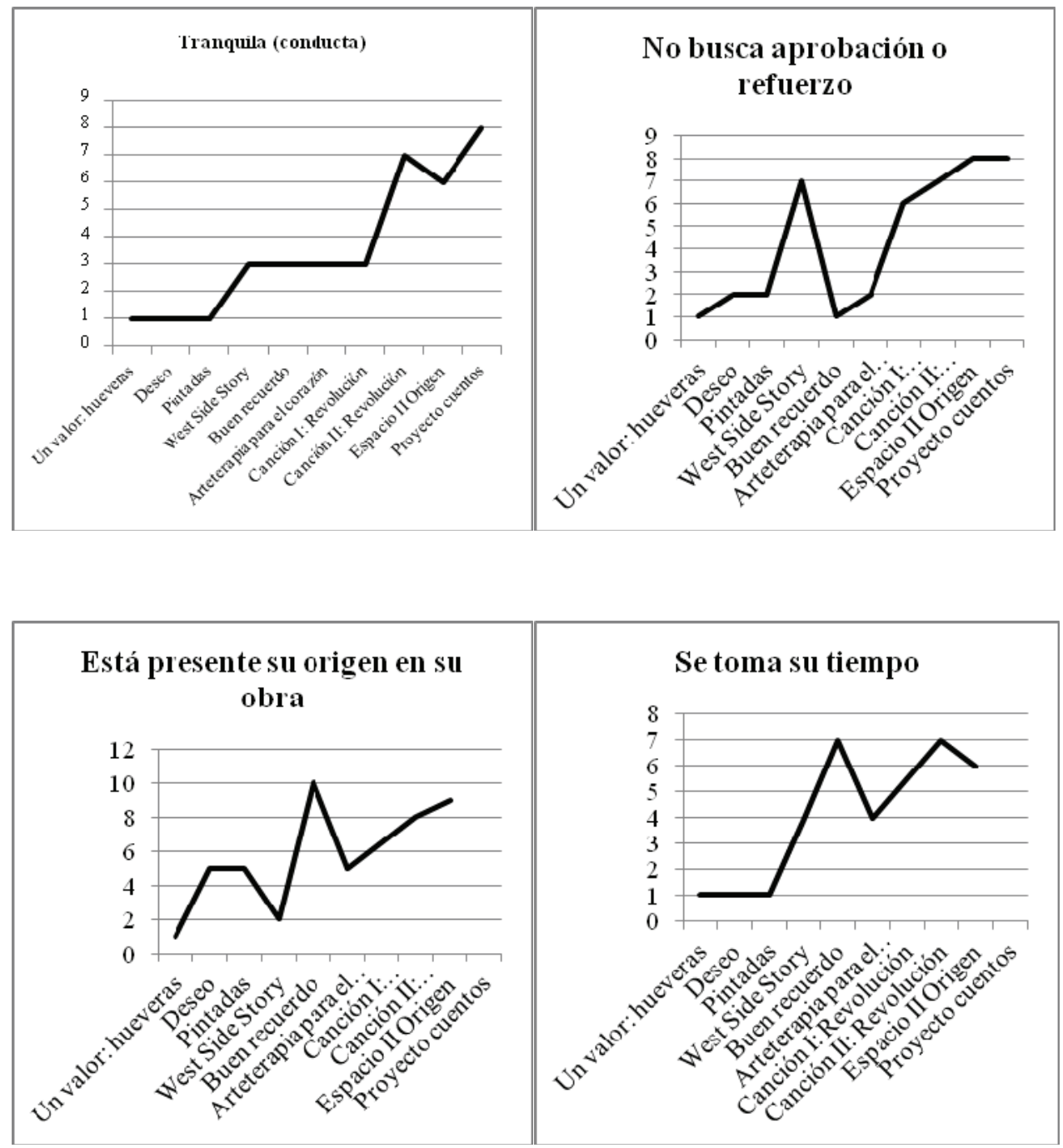


\section{REFERENCIAS BIBLIOGRÁFICAS}

CARRASCO, S (2004b). Inmigración, contexto familiar y educación: Procesos y experiencias de la población marroquí, ecuatoriana, china y senegambiana. Bellaterra (Barcelona): UniversitatAutònoma de Barcelona. Institut de Ciències de l'Educació.

GIMÉNEZ ROMERO C. (2002). Dinamización comunitaria en el ámbito de la inmigración. En: Rubio MJ y Monteros S. La exclusión social. Teoría y práctica de la intervención. Madrid: CCS 2002: 99-125.

JULIANO, D. (1998) Las que saben. Subculturas de mujeres. Madrid: Horas y Horas.

MOUALHI, D (2000) Mujeres musulmanas: estereotipos occidentales versus realidad social (2000).Papers. $\quad 60, \quad 2000 \quad 291$ 304.http://ddd.uab.es/pub/papers/02102862n60/02102862n60p291.pdf

MOGHADDAM, F. (1990). Modulative and generative orientations in psychology: Implications for psychology in the three worlds. Journal of Social Issues, 46, 21 41. Moghaddam, F. (1998). Social Psychology: Exploring universals across cultures. New York: Freeman.

PARELLA, S (2007). "Los vínculos afectivos y de cuidado en las familias transnacionales: Migrantes ecuatorianos y peruanos en España”. Migraciones Internacionales, 4 (2), 151-188.

RICO CABALLO, L (2012) Frente a la maldición de Babel. Terapia, arte y migraciones. Arteprosocial en sociedades dinámicas. Editorial Psimatica. Madrid.

RICO CABALLO, L, IZQUIERDO JAÉN, G. (2010) Arte en Contextos Especiales. Inclusión Social y Terapia a través del Arte. Trabajando con Niños y Jóvenes InmigrantesArteterapia. Papeles de Arteterapia y Educación Artística para la Inclusión Social. UCM. Madrid. Disponible en: http://revistas.ucm.es/index.php/ARTE/article/view/ARTE1010110153A/8735

RICO CABALLO, L. (2011) Ventillarte: Arteprosocial. En Arte, intervención y acción social Madrid. Editorial Grupo 5. En video: http://www.youtube.com/watch?v=KgszClZsil8

VALLE, T. (2005) Seguridad y convivencia: hacia nuevas formas de transitar y de habitar. Congreso Urbanismo y Género. Una visión necesaria para todo el mundo. Barcelona, abril 2005. www.urbanismeigenere.net. 